\title{
The convenience of nonprobability Survey strategies for small academic libraries
}

$\mathbf{R}$ ecent research on how college students use libraries has raised some interesting questions for academic librarians. Data from the report "College Students' Perceptions of Libraries and Information Resources: A Report to the OCLC Membership" illuminates how college students from around the world view libraries and what they want from libraries. Asked to increasingly justify their relevance on campus, academic libraries need to decide what services and resources to offer to students, both in person and virtually. Librarians face choices of providing students with what they want and what librarians and faculty think they need. The OCLC report drives home the need for academic libraries to both provide services that address the needs of a diverse student body and create an atmosphere where learning occurs. ${ }^{1}$ To do this, libraries must develop plans that are based on reliable information about the student body along with a sound understanding of the library's academic institution.

\section{Marketing the library}

Librarians come from a variety of disciplines with training and experience that is rich and diverse, but may not be related to marketing or business management. For those librarians not well versed in the essentials of marketing, the mere mention of the word can evoke uncertainty and fear. Despite this, it has become increasing important for librarians to understand basic marketing principles, and, in some cases, to conduct marketing research studies. Librarians are increasingly expected to understand student behavior and assess customer satisfaction, promotion, advertising, and how competition affects the future of libraries.
In other words, librarians must become adept at marketing.

If the goal is to increase student use of the library, the marketing focus must center on the needs and wants of the student. Successful marketing of the library focuses on improving the experience of the user and ultimately becomes a conversation between librarians and users, with the main focus being placed on the user experience. ${ }^{2}$ Effective marketing informs students of the library's collection and ensures they know how the library's services can help them save time and be more successful in their classes. Surveying students to determine their needs and wants enables librarians to make decisions based on data rather than anecdotal impressions, and gives perspective to where a library is and where it needs to go.

\section{Sampling methods}

There are two basic types of sampling methods used in survey research—probability sampling and nonprobability sampling. In probability sampling, every member of a population has a known, nonzero probability of being included in a sample. Surveys using this method are preferred because (if done correctly) they yield more accurate, statistically measurable results that enable researchers to draw valid conclusions reflective of a population.

The second method, nonprobability sampling, is often used by librarians to gain insight into a variety of issues related to customer satisfaction, library use, and user needs. A

Dolores Skowronek is reference librarian, e-mail: dolores. skowronek@alverno.edu, and Larry Duerr, is head librarian/public access services, e-mail: larry.duerr@ alverno.edu, at Alverno College

c 2009 Dolores Skowronek and Larry Duerr 
common type of nonprobability sampling used by librarians is convenience sampling. This method uses arbitrarily selected (rather than randomly selected) survey participants and is susceptible to bias because it does not guarantee that all eligible members of a population have an equal chance of being included in a sample.

If convenience samples do not yield statistically valid results, why would librarians rely on these types of nonprobability samples to better understand an issue? Gary T. Henry offers three reasons why researchers could justify the use of nonprobability samples-lack of resources, inability to identify members of a population, and need to establish the existence of a problem. ${ }^{3}$ In the case of research conducted by librarians, this list can be expanded to include a fourth reason—lack of research skills or experience.

Our experience collecting and analyzing data using convenience sampling at a small college library (enrollment 2,782) increased our awareness of these justifications:

- Lack of resources. Budgetary constraints, more than any other factor, often prevent small libraries from using a wellexecuted probabilistic sampling method. Using nonprobability sampling methods enables a library to limit its expenditures to cost of paper needed to print the questionnaires and librarians' salary for time spent distributing and analyzing questionnaires. Using this strategy limits the total cost of conducting a survey. ${ }^{4}$

- Need to establish the existence of a problem. Collecting survey data can identify problem areas and confirm or displace anecdotal impressions.

- Lack of research skills. New librarians may find themselves on a library marketing committee with little experience conducting survey research. For librarians fortunate enough to have had a research methods class, this could be their first opportunity to put classroom lessons into practice.

\section{Improving convenience sampling}

Carefully conducted studies that use convenience sampling can generate useful data if steps are taken to control uncertainty and bias by implementing the following improvements: control and assess the sample's representativeness, add diversity, and use more data. These improvements are outlined below:

- Sample's representativeness. Studies that use convenience sampling should attempt to reduce selection bias and strengthen the study's usefulness by controlling and assessing the representativeness of the survey sample. In other words, an attempt should be made to obtain a sample that is a miniature version of the population. Fortunately, universities and colleges tend to collect copious amounts of data on their student populations. This data provides libraries with a valuable source of reliable and current information on the entire student body and enables researchers to "take a step back and reflect on just how well the resulting sample models the intended population."

- Diversity. Diversity also adds strength to convenience samples. ${ }^{6}$ Surveys using convenience samples can attempt to achieve diversification by distributing questionnaires at various days and times in high traffic campus locations that provide access to a cross section of the student body. Additionally, an attempt should be made to be objective when distributing questionnaires by not making judgments about who should be asked to participate in the study. (For example, don't make assumptions about who is or is not a student. Give everyone present an opportunity to fill out a questionnaire.)

- Data. A third way to control uncertainty and bias is to use more data. One tactic for incorporating more data is to use larger samples. As a general rule for sample size, larger is better. For guidance, libraries can look to basic research methods texts that provide tables with suggested samples sizes for probability samples. ${ }^{?}$

\section{The survey questionnaire}

The first step in designing an effective questionnaire is setting objectives that are based upon defined needs. This step enables researchers to focus on priorities and translate 
needs into actionable decisions about what should be measured. When conducting marketing research, it is important to include questions that measure customer satisfaction as well as questions that identify the specific costs associated with using the library. In libraries, these costs can be either tangible (monetary expenses) or nontangible (value of time spent to accomplish a task, frustration, noise levels, and others). Additionally, questionnaires should also be designed to identify target audiences so libraries can better focus their marketing efforts.

Collecting demographic, geographic, and behavioral (e.g., frequency of use) data allows researchers to segment data based on the respondents' characteristics. In a college or university these characteristics can include age, level (freshman, sophomore, junior, senior, graduate student), major, zip code, and frequency of use. Including questions that segment survey respondents according to their characteristics is essential because it provides the data needed for comparison to the college's official demographic profile. The questionnaire should be tested prior to administering the survey to identify problematic and easily misunderstood questions.

\section{Data analysis}

Before survey data can be tallied and analyzed, questionnaires must first be coded. Coding is the process of "translating" survey responses into numerical codes in order to facilitate data analysis. It is a fairly straightforward process for closed questions, where the possible responses are predetermined by the researchers. These fixed responses can easily be assigned numerical codes. Closed questions work well for collecting the demographic, geographic, and frequency of use data needed to segment the survey respondents.

Open questions are good for getting unanticipated answers because they allow respondents to express themselves in their own words. These types of questions are useful when libraries are conducting exploratory research and trying to understand the intri- cacies of an issue. They also help librarians understand if differences in behavior exist among the various segments of the student body, which in turn enables librarians to identify target audiences whose behavior they wish to change or influence.

A major drawback to open questions, however, is that they can be difficult to code because each response must first be analyzed and sorted into meaningful categories. In this respect, librarians have a unique advantage because they are familiar with the process of organizing and classifying items into comparable categories. Reducing bias associated with one person's subjective point of view is an important consideration when coding open questions. To ensure the integrity of the coding process, more than one librarian should analyze open questions.

\section{Lessons learned}

The problems outlined below represent areas of concern that should be addressed by other small academic libraries wanting to use convenience samples to survey their student bodies:

- Timeline. Creating a detailed timeline that outlines all of the activities associated with implementing a survey is essential. A carefully prepared timeline should reflect the full scope of the survey process and include commitments from individual staff members. This will help ensure that momentum and motivation are maintained as the process moves from start to finish.

- Matching questionnaire categories. Questionnaires that use the same categories as the college to collect data enable libraries to assess how well a sample represents the actual student population. For this reason, it is essential that libraries use an accurate and reliable source of college data when designing their questionnaires.

- Frequency of use parameters. A challenge for academic libraries is defining the "nonuser". We have found that a questionnaire that measured frequency of use using the parameter of "once a semester or less" is a reliable way of measuring nonuse. 
- Seeking guidance. Take full advantage of the skill levels of other campus administrators and faculty. This area cannot be underestimated. The tasks associated with implementing a library survey can be made much easier if the college administration is willing to share enrollment statistics, and more importantly, explain how college data is collected. Librarians should also tap the expertise of faculty and get advice on the validity of the library's data.

\section{Final thoughts}

The Merriam-Webster Online Dictionary offers this definition of convenience: "designed for quick and easy preparation or use." While it does make the process less rigorous, library surveys that use convenience samples are still challenging because they require research skills, commitment, patience, and perseverance. These challenges, however, should not discourage librarians from attempting surveys of their own. Being an instrumental part of a research project that brings about improvements to the library can be rewarding from many perspectives. Not only will positive change elevate the presence of the library in the eyes of faculty and college administration, but it will also have a profound impact on the quality of learning for all members of the student body.

\section{Acknowledgments}

The authors wish to thank Carol Brill, Jeff Desannoy, Maureen Schinner, and Kris Vasquez for their invaluable assistance and guidance.

("Banned Books" continues from page 392) to the cultural environment of the campus. Banned Books Week has become a very popular event in the campus community, and we will continue to hold and promote readings in future years. We also plan to create other Web sites about different events in the long history of book banning, showing the depth and variety of the collection. We hope that this will raise awareness about the research potential of the Freedom of the Press Collection among undergraduates and other community members who may not be aware

\section{Notes}

1. Cathy De Rosa and others, "College Students' Perceptions of Libraries and Information Resources," A Report to the OCLC Membership (OCLC, 2006), www.oclc.org /reports/pdfs/studentperceptions.pdf (accessed August 14, 2008).

2. Barbara Whitney Petruzzelli, ed. RealLife Marketing and Promotion Strategies in College Libraries (Binghamton, NY: Haworth Information Press, 2005), Elizabeth Kennedy Hallmark, Laura Schwartz , and Loriene Roy, "Developing a Long-Range and Outreach Plan for your Academic Library" College and Research Library News 68, No. 2 (2007): 92-95.

3. Gary T. Henry, Practical Sampling (Newberry Park, CA: Sage, 1990), 24.

4. The total cost of a recent survey the authors conducted was less than $\$ 600$.

5. Ann Aileen O'Connell, "Sampling for Evaluation: Issues and Strategies for Community-Based HIV Prevention Programs," Evaluation \& the Health Professions 23 No. 2 (2000): 220.

6. Mildred L. Patten, Proposing Empirical Research: A Guide to the Fundamentals 2nd ed. (Los Angeles: Pyrczak, 2002), 65.

7. Ronald R. Powell, and Lynn Silipigni Connaway, Basic Research Methods for Librarians 4th ed. (Westport, CT: Libraries Unlimited, 2004), 107.

8. Convenience, Merriam-Webster Online Dictionary, www.merriam-webster.com /dictionary (accessed August 2, 2008). n

of the value of primary source materials.

\section{Notes}

1. The 2009 Banned Books Week will be held September 26-October 3.

2. Special Collections Research Center, lib. siu.edu/departments/speccoll.

3. ALA Web site for Banned Books Week, ala.org/bbooks.

4. cryptomundo.com/cryptozoo_news/banbfbkwk.

5. www.law.siu.edu/lawlib/Banned $\% 20$ Books/intro.asp. $\pi$ 